\section{Commentary: Anatomical partial lobectomy: The indications should be better defined}

\author{
Yang Zhang, MD, and Haiquan Chen, MD, PhD
}

The traditional standard surgical procedure for stage IA non-small cell lung cancer is lobectomy. However, along with the wide application of computed tomography, there is an increased detection of small-sized early-stage lung cancer. ${ }^{1}$ The necessity of lobectomy has been questioned. Our previous study showed intraoperative frozen section could precisely diagnose pre- and minimally invasive lung adenocarcinoma. Sublobar resection for patients with preand minimally invasive lung adenocarcinoma could achieve a 5-year recurrence-free survival of $100 \%{ }^{2}$ The JCOG0804 trial evaluated the efficacy of sublobar resection for patients with tumor size $\leq 2 \mathrm{~cm}$ and consolidation tumor ratio $\leq 0.25$ peripheral lung cancer, and showed that these patients had a 5-year relapse-free survival of $99.7 \%$. ${ }^{3}$ The JCOG0802 trial is a randomized trial comparing segmentectomy with lobectomy for patients with peripheral tumor size $\leq 2 \mathrm{~cm}$ and consolidation tumor ratio $>0.5$ lung cancer. It showed that survival after segmentectomy is noninferior to lobectomy. However, the local recurrence after segmentectomy was much higher than lobectomy $(10.5 \%$ vs $5.4 \%){ }^{4}$ These findings suggest that even for small peripheral lung cancer, sublobar resection cannot be deemed as radical surgery for all patients.

Doctors from the Chinese Academy of Medical Sciences Cancer Institute and Hospital proposed the concept of

\footnotetext{
From the Departments of Thoracic Surgery and State Key Laboratory of Genetic Engineering, Fudan University Shanghai Cancer Center, Shanghai, China; and Institute of Thoracic Oncology, and Department of Oncology, Shanghai Medical College, Fudan University, Shanghai, China.

Disclosures: The authors reported no conflicts of interest.

The Journal policy requires editors and reviewers to disclose conflicts of interest and to decline handling or reviewing manuscripts for which they may have a conflict of interest. The editors and reviewers of this article have no conflicts of interest.

Received for publication Nov 14, 2021; revisions received Nov 14, 2021; accepted for publication Nov 17, 2021; available ahead of print Nov 20, 2021.

Address for reprints: Haiquan Chen, MD, PhD, Department of Thoracic Surgery, Fudan University Shanghai Cancer Center, 270 Dong-An Rd, Shanghai 200032, China (E-mail: hqchen1@yahoo.com).

J Thorac Cardiovasc Surg 2022;164:648-9

$0022-5223 / \$ 36.00$

Copyright (c) 2021 by The American Association for Thoracic Surgery

https://doi.org/10.1016/j.jtcvs.2021.11.033
}

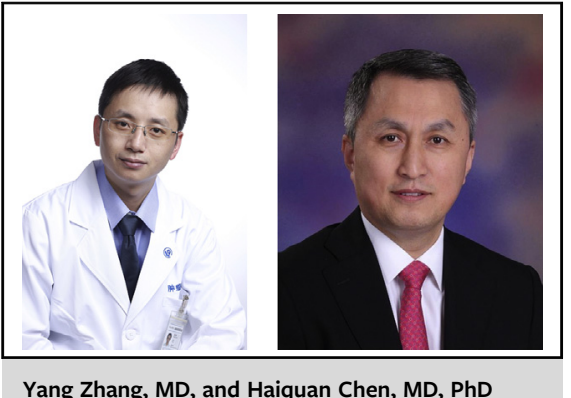

Yang Zhang, MD, and Haiquan Chen, MD, PhD

CENTRAL MESSAGE

$A P L$ is a safe and feasible surgical

procedure. Further studies are

warranted to better define the

indications of APL with the aim

of letting the patients live longer

and live better.

anatomical partial lobectomy (APL), which focused on the oncological margin and territory of corresponding bronchi or vessels. ${ }^{5}$ The authors presented the short-term outcomes after APL in a large series of 3336 patients. Impressively, there was no surgery-related mortality. The morbidity rate was $10.8 \%$, and most of them were Common Terminology Criteria for Adverse Events grade 1 or 2. These results supported APL as a safe procedure. We believe that oncological margin is very important when performing segmentectomy. For some patients, standard segmentectomies are not able to achieve safe margins. These patients might benefit from APL.

Limitations of this study should also be noted, which require further research. First, there was no control group. The safety and efficacy of APL should be compared with a standard procedure. Second, long-term results are unknown. Because the JCOG0802 trial showed a high recurrence rate in the segmentectomy group, the recurrence and overall survival data after APL should be assessed in future studies. Last and most importantly, the indications of APL should be better defined. More than $40 \%$ of these patients had benign lesions, or pre-/minimally invasive adenocarcinoma. Pre- and minimally invasive adenocarcinoma can have a 5 -year postoperative recurrence-free survival of $100 \%$, regardless of the surgical procedures. ${ }^{2}$ These patients might just have wedge resection, which is a simpler procedure and preserves the normal structure of the hilum. However, 
patients who have a high risk of developing local recurrence might need lobectomy. The authors should clarify what kind of patients are best suitable for APL.

On the basis of the results of this large-sample study, APL is a safe and feasible surgical procedure. Further studies are warranted to better define the indications of APL with the aim of letting the patients live longer and live better.

\section{References}

1. Zhang Y, Jheon S, Li H, Zhang H, Xie Y, Qian B, et al. Results of low-dose computed tomography as a regular health examination among Chinese hospital employees. J Thorac Cardiovasc Surg. 2020;160:824-31.e4.
2. Liu S, Wang R, Zhang Y, Li Y, Cheng C, Pan Y, et al. Precise diagnosis of intraoperative frozen section is an effective method to guide resection strategy for peripheral small-sized lung adenocarcinoma. J Clin Oncol. 2016;34:307-13.

3. Suzuki K, Watanabe SI, Wakabayashi M, Saji H, Aokage K, Moriya Y, et al. A single-arm study of sublobar resection for ground-glass opacity dominant peripheral lung cancer. J Thorac Cardiovasc Surg. Published online November 12, 2020. https://doi.org/10.1016/j.jtcvs.2020.09.146

4. Asamura H, Okada M, Saji H, Tsuboi M, Nakajima R, Suzuki K, et al Randomized trial of segmentectomy compared to lobectomy in small-sized peripheral non-small cell lung cancer. Paper presented at: 101st Annual Meeting of American Association for Thoracic Surgery: A Virtual Learning Experience; April 30-May 2, 2021. AATS; 2021.

5. Qiu B, Ji Y, Zhang F, Bai G, Xue Q, Polaczek M, et al. Outcomes and experience of anatomical partial lobectomy. J Thorac Cardiovasc Surg. 2022;164: 637-47.e1. 